\title{
Conflitos de interesse na pesquisa, produção e divulgação de medicamentos
}

\section{Conflicts of interest in the research, production and dissemination of medicines}

\author{
Alexandre Palma \\ Professor do Programa de Pós-graduação em Educação Física \\ Universidade Federal do Rio de Janeiro (UFRJ). \\ Av. Carlos Chagas Filho, 540 \\ 21941-599 - Rio de Janeiro - RJ - Brasil \\ palma_alexandre@yahoo.com.br

\section{Murilo Mariano Vilaça} \\ Doutorando do Programa de Pós-graduação em Filosofia/UFRJ. \\ Largo de São Francisco, $n^{\circ} 1$, sala 303-C \\ 20051-070 - Rio de Janeiro - RJ - Brasil \\ contatoacademico@hotmail.com
}

Recebido para publicação em agosto de 2010. Aprovado para publicação em setembro de 2011.
PALMA, Alexandre; VILAÇA, Murilo Mariano. Conflitos de interesse na pesquisa, produção e divulgação de medicamentos. História, Ciências, Saúde - Manguinhos, Rio de Janeiro, v.19. n.3, jul.-set. 2012, p.919-932.

\section{Resumo}

Analisa o debate sobre os conflitos éticos dos artifícios utilizados pela indústria farmacêutica na pesquisa, produção e divulgação dos medicamentos. Três aspectos são examinados: o envolvimento dos profissionais de medicina com os representantes das indústrias farmacêuticas; o conflito de interesses quanto a sua atuação como patrocinadora de pesquisas científicas; a avaliação de fármacos em seres humanos. Verifica-se que a mensagem para promoção da saúde advém da medicalização; as grandes indústrias farmacêuticas não produzem exclusivamente mercadorias, mas, sobretudo, subjetividades. Dessa forma, descortina-se o tipo de ordem por elas estabelecida.

Palavras-chave: indústria farmacêutica; medicamentos; bioética; conflito de interesses.

\section{Abstract}

This paper analyzes the debate about the ethical conflicts of the methods used by the pharmaceutical industry in the research, production and dissemination of medicines. Three aspects are examined: the involvement of medical professionals with representatives of the pharmaceutical industry; the conflicts of interest regarding their role as sponsors of scientific research; and the evaluation of drugs on human beings. It is seen that the message for health promotion comes from medicalization; the major pharmaceutical industries do not exclusively produce merchandise, but especially subjectivities. In this way, the type of order established by them is revealed.

Keywords: pharmaceutical industries; medication; bioethics; conflicts of interest. 
Frequentemente as pessoas - sejam profissionais ou leigas - são surpreendidas com uma nova informação sobre determinado produto farmacêutico, desenvolvido e divulgado como a solução para os problemas de inúmeros indivíduos.

Em que pese a importância das frequentes descobertas, não raro somos confrontados com outra realidade, em cujo contexto tais invenções parecem inócuas ou se mostram confusas, uma vez que, constantemente, a comunidade científica se depara com estudos cujos resultados são conflitantes.

Recentemente, foram postos à prova os benefícios dos medicamentos antidepressivos (Kirsch et al., 2008) e, no Brasil, cancelado o registro do anti-inflamatório Prexige ${ }^{\circledR}$ (Anvisa, 2008). Contudo, diversas outras investigações científicas têm discutido os possíveis riscos e benefícios do uso de determinados medicamentos, como é o caso do anti-inflamatório Vioxx ${ }^{\circledR}$ (Graham et al., 2005; Pearce, 2008) e do tratamento de reposição hormonal (Schairer et al., 2000).

A leitura do livro A verdade sobre os laboratórios farmacêuticos, de autoria de Marcia Angell (2007) - respeitada pesquisadora do Departamento de Medicina Social da Harvard Medical School e ex-editora-chefe do The New England Journal of Medicine -, e do artigo Corporate influences on epidemiology, no periódico International Journal of Epidemiology escrito por Neil Pearce (2008), presidente da International Epidemiological Association, remete a importantes questões éticas envolvendo as indústrias farmacêuticas, os médicos e os pesquisadores.

Barros (2008) destaca igualmente que, após um progressivo avanço tecnológico subordinado à lógica do mercado, os medicamentos têm servido menos aos propósitos sanitários do que aos interesses de geração de uma crença desmesurada e acrítica em seus poderes.

Tal discussão não é nova. Já nos anos 1970, Ivan Illich $(1975$, p.6) afirmava que "A empresa médica ameaça a saúde, a colonização médica da vida aliena os meios de tratamento, e o seu monopólio profissional impede que o conhecimento científico seja partilhado".

Desse modo, o presente ensaio objetiva trazer à tona o debate sobre os conflitos éticos decorrentes dos artifícios utilizados pela indústria farmacêutica na pesquisa, produção e divulgação dos medicamentos.

\section{Risco à saúde, segurança para os negócios}

Os argumentos de Angell (2007) desmitificam, ao menos para o público em geral, as ações das indústrias farmacêuticas. No rastro dessas ideias, vários outros textos têm sido publicados, entre eles, o de Pearce (2008) em que o coro daqueles que se preocupam com a proximidade entre as indústrias farmacêuticas e a pesquisa científica é reforçado. Roy Moynihan (2003a, 2003b), importante crítico da atuação das companhias farmacêuticas, também discute com propriedade alguns pontos relevantes.

De imediato, três aspectos devem ser destacados. O primeiro, amplamente debatido por Moynihan (2003a, 2003b), diz respeito ao estranho convívio entre a indústria farmacêutica e os médicos. De acordo com Carl Elliott (2010), autor de um livro cujo título - bastante 
sugestivo e irônico por sinal (White coat, black hat: adventures on the dark side of medicine) já indica a problemática relação supracitada, o New England Journal of Medicine afirma que $80 \%$ dos ensaios patrocinados pelas indústrias farmacêuticas foram realizados em centros de pesquisa acadêmicos. Além disso, ainda segundo esse autor, tais indústrias costumam proceder do seguinte modo: elas próprias desenvolvem uma droga, para, em seguida, arregimentar médicos acadêmicos visando à realização de testes clínicos. Tendo em vista que tais modalidades de 'cooperação' envolvem alguma contrapartida financeira e/ou melhoria de laboratórios, essa estratégia, podemos cogitar, se apresenta mais como uma mera formalidade com fins de validação de um fármaco já desenvolvido e menos como perscrutação epistemológica e eticamente criteriosa e comprometida, o que implicaria a total liberdade de proscrevê-lo.

Assim, insinua-se uma espécie de acordo de cooperação bilateral, gerando benefícios a ambas as partes. Os centros interessam às empresas, na medida em que oferecem pesquisadores para projetar e assinar testes clínicos e publicações em periódicos renomados estratégia que legitima e propagandeia seus produtos - e grupos de potenciais sujeitos de pesquisa; já a contrapartida dada pela indústria, nos termos supracitados e possivelmente em outros, serve como um grande chamariz, o que parece comprometer a autonomia acadêmico-científica. Uma questão que pode ser formulada é se esse acordo produz, de fato, benefícios para os sujeitos, que não deveriam, ao menos na condição de seres humanos, ser prejudicados - ainda que não fossem beneficiados, deveriam ser protegidos -, ou se esses, tratados como clientes nessa relação de cunho criptoempresarial, são inescrupulosamente expostos a riscos.

Tal relação de codependência é marcada por uma flagrante desigualdade econômica, se levarmos em conta o fato de que as indústrias farmacêuticas detêm meios econômicos para promoção das (custosas) pesquisas que são incomparavelmente superiores aos daqueles centros acadêmicos. Ainda que essa relação se apresente como epistemológica e eticamente questionável - pois as pesquisas podem ser viciadas, o que pode implicar riscos à saúde dos sujeitos que farão uso dos produtos resultantes (os fármacos) - ela não satisfaz completamente os anseios das indústrias. Conforme argumenta Elliott (2010), impacientes com a 'burocracia acadêmica' - expressão usada em referência aos resquícios de critérios ainda vigentes no meio acadêmico para garantir a fidedignidade e a segurança das pesquisas - as companhias farmacêuticas, em 2004, conduziam 70\% das pesquisas de testagem de novas drogas por meio de financiamento próprio.

O envolvimento dos profissionais de medicina com os representantes das indústrias cria embaraço na atuação dos primeiros. Sem dúvida, presentes, viagens, financiamento para congressos podem ser considerados um tipo de suborno e, tendo em vista o fato de as empresas, obviamente, estarem motivadas pelo lucro e não exatamente por ações altruístas, é preciso ter cautela ao apreciar essas atitudes.

Moynihan (2003a) alega que há cerca de oitenta mil representantes das indústrias farmacêuticas nos Estados Unidos. De acordo com Willerroider (2004), na Alemanha, existem 17 mil representantes dos laboratórios para aproximadamente 130 mil médicos, isto é, uma razão de 7,64 médicos para cada promotor de vendas. Segundo a autora, essa relação de cerca de sete médicos para cada representante da indústria farmacêutica é similar na 
França, na Grã-Bretanha e nos Estados Unidos, número que parece extremamente elevado, sendo representativo da importância que o setor de marketing das empresas vem conquistando (Angell, 2007).

No Brasil, essa questão não parece ser diferente. Fagundes et al. (2007), ao investigarem a influência da publicidade dos medicamentos na categoria médica, observaram que $98 \%$ dos cinquenta médicos participantes da pesquisa recebem, com regularidade, a visita de representantes comerciais, sendo que $40 \%$ as recebem semanalmente. Além disso, 86\% recebem brindes dos propagandistas da indústria farmacêutica, e 14\% informaram tomar decisões sobre a prescrição, influenciados pelos prêmios recebidos.

Em outro estudo realizado no Brasil, Barros e Joany (2002) analisaram os anúncios de medicamentos em importantes revistas médicas brasileiras. Os autores constataram que pouco mais de $30 \%$ das 1.774 páginas das revistas se destinavam às propagandas de medicamentos e que poucos anúncios referiam-se às reações adversas ou contraindicações. Além disso, os critérios propostos pela Organização Mundial da Saúde (OMS) para as propagandas de medicamentos não eram cumpridos na íntegra. Por fim, os autores destacaram que a atitude acrítica dos médicos em face das estratégias de mercado das indústrias farmacêuticas está associada à baixa qualidade da prescrição dos medicamentos.

Essa questionável relação também tem permeado acordos entre instituições médicas e outras empresas comerciais. Brody (2010) comenta, por exemplo, as relações estabelecidas entre a American Academy of Family Physicians e a Coca-Cola. O autor pondera que há nesse caso um claro conflito de interesse e, embora os defensores dessa vinculação argumentem que a instituição médica poderia forçar a empresa de refrigerantes a ter atitudes mais responsáveis - como, por exemplo, a de prover campanhas educativas - é razoável imaginar que pode haver um decréscimo de confiança na entidade médica, uma vez que a Coca-Cola não representa propriamente uma empresa que contribui para a promoção da saúde, fim último daquela instituição.

Um segundo aspecto ético relacionado aos textos de Pearce (2008) e de Moynihan (2003a, 2003b) refere-se ao conflito de interesses envolvendo a indústria farmacêutica como patrocinadora de pesquisas científicas. Cabe ressaltar que a pesquisa financiada com verba direta das empresas interessadas em seus resultados coloca em questão suas conclusões e, talvez seja, como advogou Pearce (2008), a maior ameaça à integridade das investigações científicas. Segundo Angell (2007), para justificar que um fármaco é mais eficaz que outros, as investigações, rotineiramente, são conduzidas para encontrar resultados favoráveis. Os estudos que não confirmam essa eficácia, conforme alerta a autora, muito provavelmente não são publicados. A estimativa de que $60 \%$ da pesquisa biomédica nos EUA recebe financiamento privado, como ressaltou Moynihan (2003a), pode ser um reflexo dessa conduta.

Martinson, Anderson e de Vries (2005), em investigação sobre pesquisadores norteamericanos, estudaram as condutas que ameaçam a integridade da prática científica. Os autores observaram que, entre outras condutas reprováveis, 15,5\% dos informantes manifestaram alterar desenho, método ou resultados das pesquisas em resposta às pressões dos financiadores. Os achados sugerem que boa parte (33\%) dos cientistas norte-americanos 
está engajada em algum tipo de comportamento que envolve falsificação, fabricação e/ou plágio de dados que, obviamente, revela um conflito de interesses.

No debate promovido pelo International Journal of Epidemiology, Hass (2008), em defesa das relações entre as indústrias farmacêuticas e a epidemiologia, argumentou que, apesar de necessário para desenvolver e avaliar novos e antigos medicamentos, o estudo de origem acadêmica não garante objetividade ou rigor científico e que, por exemplo, estudos epidemiológicos comprometidos são, frequentemente, imputados à pesquisa financiada pela indústria.

Por certo, diferentes interesses podem ser postos em jogo, não somente aqueles advindos dos financiamentos de laboratórios farmacêuticos. Bruno Latour e Steve Woolgar (1997), cientistas sociais que pesquisaram um importante laboratório de investigação científica norte-americano, descreveram de forma original os diferentes 'padrões de crédito' que favorecem determinados grupos de pesquisa, envolvendo ganhos financeiros, citações dos estudos, destaque entre os pares da comunidade científica, corrida pelo prêmio Nobel, entre outros aspectos.

Atualmente, uma das tarefas fundamentais da ciência é reformular seus olhares em relação aos problemas emergentes, reconhecendo a incerteza e a complexidade que guiam o conhecimento científico. Nesse sentido, Funtowicz e Ravetz (1994) consideram que, em geral, a ciência não fornece teorias bem fundamentadas para explicar e prever a ocorrência de determinados problemas, pois as 'predições científicas' apresentam elevado grau de incerteza e dependem de grande número de aspectos imprevisíveis.

Apesar de tais ponderações, é preciso questionar em qual situação se poderia obter mais liberdade para a pesquisa: sob os auspícios da universidade ou da indústria? Decerto, acreditamos que a maior independência ocorreria no primeiro caso.

Moynihan (2006) cita, por exemplo, que o International Obesity Task Force, em associação com outro grupo denominado International Association for the Study of Obesity, manteve laços significativos com a OMS. Entretanto, dois terços do total de financiamento de pesquisas sobre obesidade advieram de duas grandes companhias farmacêuticas interessadas, a Roche, fabricante do Xenical ${ }^{\circledR}$, e a Abbott, que produz o Reductil®.

Algumas pesquisas podem ainda ser conduzidas com o único intuito de criar um novo mercado para a utilização dos medicamentos. Angell (2007) destaca essa situação ao expor suas considerações acerca dos medicamentos para a ansiedade social ou para o 'transtorno da disforia pré-menstrual'. As ponderações de Moynihan (2004) são igualmente relevantes. O autor (Moynihan, 2003c) publicou no Britisth Medical Journal um artigo no qual analisa a criação e a fabricação do Viagra ${ }^{\circledR}$ para o sexo feminino sem que, no entanto, houvesse uma clara definição do que seja uma disfunção sexual entre mulheres. Barros (2008) enfatiza que a evolução científica e tecnológica parece impor a 'patologização' de condições fisiológicas naturais, de tal modo que a calvície, o envelhecimento ou mesmo o sobrepeso tornaram-se doenças.

No Brasil, Nishioka (2008) lembra que, a despeito da falta de tradição na realização de ensaios clínicos pela indústria farmacêutica nacional, o panorama tende a mudar, 
destacando a importância do acompanhamento de ensaios clínicos com medicamentos produzidos no país, bem como o monitoramento de seus eventos adversos.

Um terceiro e não menos importante aspecto ético diz respeito à avaliação de fármacos em seres humanos, especialmente em países não desenvolvidos. Desse modo a mídia brasileira, ao mesmo tempo em que traz à tona, em tom de entusiasmo, a informação de que cerca de 250 mil indivíduos participam atualmente como "cobaias humanas" em pesquisas de novos medicamentos (Awi, 2 mar. 2008), enfatiza que abusos têm sido cometidos em nome da ciência, principalmente, por empresas multinacionais que não podem empregar, em seu próprio quintal, os procedimentos metodológicos que utilizam em países mais vulneráveis. O filme $O$ jardineiro fiel (The constant gardener, 2005), dirigido por Fernando Meirelles, retrata, de modo exemplar, essa questão. Grande parte dos ensaios clínicos é feita em países não desenvolvidos, em que sua realização é mais barata, fácil e ágil. Mais interessante ainda é constatar que poucas investigações têm sido conduzidas com o intuito de encontrar e produzir medicamentos que atendam às necessidades dos países 'fornecedores' de cobaias, como tratamentos para malária ou esquistossomose, pois esses não trariam compensação financeira (Angell, 2007).

Quanto a esse aspecto, cabe uma observação. Recorrer a sujeitos em situação de vulnerabilidade, em especial vulnerabilidade socioeconômica, não é um procedimento restrito aos países não desenvolvidos. Outra estratégia, que se aplica, por exemplo, ao caso norteamericano - mas não, ou pelo menos não oficialmente, ao brasileiro - é o pagamento oferecido aos que participam de pesquisas com drogas. De acordo com Elliott (2010, p.2), em cidades como Filadélfia e Austin (EUA), a "economia de testes de drogas" tem produzido uma "comunidade de sujeitos de pesquisa semiprofissionais". ${ }^{1}$ Os sujeitos que compõem essa comunidade são, predominantemente, desempregados, estudantes, trabalhadores com contrato de trabalho precário e ex-presidiários.

Para nós, tal relação envolve um tipo inconfundível de conflito de interesses, quiçá um dos mais dramáticos, tendo em vista que o interesse em (ou necessidade de) sobreviver faz com que, diante da impossibilidade de prover o próprio sustento por meio de um trabalho, a pessoa opte por atuar como agente indutor, arriscando a saúde, reiteradas vezes, em troca de algumas dezenas de dólares. James Rockwell, um desses sujeitos de pesquisa semiprofissionais, afirma ter-se inscrito em mais de duas dezenas de estudos que envolviam recompensa monetária, sobretudo aqueles mais invasivos, que são mais bem remunerados (Elliott, 2010).

De acordo com Illich (1975), o governo de Salvador Allende, no Chile, foi o único, no mundo ocidental, a tentar colocar freio no avanço abusivo dos fármacos, ao propor a proibição da importação de novos medicamentos sem que tivessem sido testados por ao menos sete anos na população norte-americana e com a condição de que nunca tenham sido proibidos pela Food and Drug Administration (FDA).

É preciso, portanto, repensar a proximidade das relações entre indústria farmacêutica, ciência e medicina, a despeito das possíveis contribuições dessa indústria para melhorar a saúde e a qualidade funcional da vida de diferentes populações ou mesmo da sua cooperação com programas educacionais e/ou profissionalizantes. 
Talvez seja necessário e urgente, em especial, livrar o debate dos argumentos ingênuos, que não expõem claramente que as indústrias farmacêuticas têm lucros excessivos e que inflacionam os custos da produção. Assim, o discurso romântico de Hass (2008) coadunase mais com a idolatria dos mercados livres do que com a paixão pelo bom andamento da ciência.

\section{Em nome da saúde}

As informações mencionadas, embora causem espanto, têm sido respaldadas por um discurso metonímico em nome da saúde que oculta, de modo muitas vezes imprudente, as reais intenções de lucro financeiro por parte das indústrias farmacêuticas.

Embora haja tipos distintos de medicalização, segundo a análise histórico-genealógica dos procedimentos de medicalização feita por Foucault (2007), a partir da aproximação com outros fenômenos sociais, a medicalização da sociedade tem como objetivo analisar tudo que pode gerar um conjunto de males (doenças, revoltas, violência, criminalidade); controlar a circulação não só de indivíduos, mas também de bens e outras coisas (por exemplo, mercadorias, bactérias, rebeliões etc.); e, por fim, organizar, distribuir e sequenciar tudo, configurando uma medicina dos modos de vida, das formas de existência.

O poder político da medicina, segundo Foucault (2007, p.89),

consiste em distribuir os indivíduos uns ao lado dos outros, isolá-los, individualizá-los, vigiá-los, um a um, constatar o estado de saúde de cada um, ver se está vivo ou morto e fixar, assim, a sociedade em um espaço esquadrinhado, dividido, inspecionado, percorrido por um olhar permanente e controlador por um registro, tanto quanto possível completo, de todos os fenômenos.

Esse trecho, à primeira vista relacionado ao problema das pestes, insinua ou talvez indica que uma série de elementos vinculados aos mecanismos médicos passou a atuar em campo mais amplo, no controle social, o que evidencia que a medicina - entendida como técnica geral de saúde - assumiu um lugar cada vez mais importante na maquinaria de poder a partir do século XVIII. De acordo com a interpretação foucaultiana da modernidade, nasce ali um tipo de poder ligado a um saber médico-administrativo

\footnotetext{
acerca da sociedade, de sua saúde e suas doenças, de sua condição de vida, de sua habitação e de seus hábitos ... uma ascendência político-médica sobre uma população que se enquadra como uma série de prescrições que dizem respeito não só à doença, mas às formas gerais da existência e do comportamento (a alimentação e a bebida, a sexualidade e a fecundidade, a maneira de se vestir, a disposição ideal do habitat) (Foucault, 2007, p.202).
}

Afinal, isolar, individualizar, fixar (em um domicílio, por exemplo), esquadrinhar, dividir, inspecionar, controlar, registrar etc. são ações ligadas a práticas que visam à promoção de um minucioso controle social, pautado sobretudo na previdência, e diretamente ligado ao saber médico.

A mensagem é clara e direta: para promover a saúde é preciso medicalizar. Tal procedimento de gestão de populações humanas é chamado por Foucault (2007) de medicalização. Por esse conceito entende-se um complexo, indefinido e contínuo processo de normalização 
biopolítica que envolve uma série de práticas, cujos fundamentos estão nos procedimentos médicos, tendo função política de regular condutas, comportamentos e a própria vida biológica - incluindo os corpos - para além do âmbito das enfermidades. Nessa concepção, a saúde está diretamente relacionada à noção de bem-estar da população em geral, constituindo, em bloco, saúde bem-estar, um dos objetivos essenciais do poder político.

Duas são as noções básicas por meio das quais Foucault (2007) analisa essa tecnologia de controle social, pensada a partir da análise do saber médico. $\mathrm{O}$ autor, que elabora sua análise a partir de uma genealogia da medicina social, estabelece algumas bases para se pensar a história da saúde pública. No tocante à constituição da noção de biopolítica, que guarda relação com a medicalização da sociedade instaurada pela ideia de saúde pública, ele afirma que, se o corpo é uma realidade biopolítica, a medicina é uma estratégia biopolítica. Outro importante ponto destacado por ele na pesquisa sobre a política de saúde no século XVIII pode ser compreendido pelo que se denomina nosopolítica. E é justamente por meio da identificação e da análise das mudanças que a modernidade operou na nosopolítica que Foucault (2007) aponta as características da medicalização moderna das populações, das sociedades humanas.

De acordo com o autor, o fenômeno em evidência no século XVIII é o deslocamento progressivo dos procedimentos mistos e polivalentes de assistência à saúde. O objetivo central era operar um esquadrinhamento mais rigoroso das populações. Para tanto, duas novidades inter-relacionadas foram instauradas. Por um lado, houve a separação entre pobreza e doença; por outro, estabeleceu-se um novo quadro de distinções, de diferenciações categoriais e/ou funcionais, no qual a figura do pobre foi substituída pela dos bons ou maus pobres, dos ociosos voluntários e dos desempregados involuntários etc. Em vez da pobreza, o que emerge como um problema ou uma categoria é a 'ociosidade'. Preocupandose com suas condições e efeitos, a nova nosopolítica visa basicamente à produtividade, ainda que guarde uma estreita relação com a pobreza, uma vez que as condições à época, e até os dias de hoje, a reproduzem. Pretendia-se, por um lado, primordialmente, tornar a pobreza útil, fixando-a nos aparelhos de produção por intermédio de um mínimo de vida saudável, isto é, uma vida que tornasse os indivíduos capazes de produzir; ou, por outro lado, aliviasse ao máximo o peso que representam os pobres para o restante da sociedade.

Essas novas regras, que são, para Foucault (2007), fruto da problematização da nosopolítica ocorrida no século XVIII, traduzem a organização progressiva da 'grande medicina' no século XIX que, por sua vez, é corporificada por "uma política de saúde e de consideração das doenças como um problema político e econômico" (p.194). Tal política de assistência não enfoca somente os pobres como alvo de assistência, e sim a coletividade como um todo, ou seja, buscam-se efeitos de conjunto que atinjam toda uma população. Segundo Foucault (2007), o objetivo geral deve ser compreendido como "a saúde de todos como urgência para todos; o estado de saúde de uma população" (p.195). Em outras palavras, é aquilo que podemos chamar de 'imperativo da saúde', um dever de cada um, um propósito geral da razão de estado, da governamentalidade biopolítica liberal.

Na medicalização biopolítica da sociedade, uma série funcional deve ser implementada e mantida ciosamente: a disposição da sociedade como meio de 'bem-estar físico, saúde 
perfeita e longevidade'. Essa tríplice função foi exercida por um aparelho que conjugava mecanismos de garantia da ordem, desenvolvimento canalizado das riquezas e promoção da saúde em geral, a saber, a polícia (Foucault, 2007). Tendo em vista o foco do presente artigo, entre as múltiplas atividades da polícia destaca-se o papel de preservar o respeito, o cumprimento das regras gerais de higiene. Conforme Foucault defende, o privilégio dado à higiene marca a nosopolítica moderna; é um traço destacado do funcionamento da política médica como instrumento de controle social. Pensar a medicalização no seu nascedouro é remeter-se à higiene como um regime de saúde de populações, um regime que envolve práticas profiláticas, aplicado ao conjunto de uma população, a fim de fazer desaparecerem os surtos epidêmicos, baixar a taxa de morbidade e aumentar a duração da vida.

Associado por Foucault (2007) à governamentalidade biopolítica, isto é, à gestão por governamentos da vida dos homens enquanto indivíduos de uma espécie, o ato de medicalizar uma sociedade consiste basicamente em gerir o quadrinômio caso-risco-perigocrise pela lógica dos dispositivos de segurança, fundamentalmente por meio de práticas preventivas que melhoram a vida, promovendo a saúde e o bem-estar de uma população.

Para Foucault (2005), a economia contemporânea da biopolítica opera de acordo com a lógica de que o poder consiste cada vez menos no direito de fazer morrer e cada vez mais no direito de interferir para conservar a vida. Essa biopolítica levará à criação de instituições assistencialistas e de mecanismos sutis e mais racionais economicamente. Entre eles está a capacidade de as indústrias farmacêuticas criarem alvos terapêuticos ou, ainda, a exigência de cuidar de si. Assim, essa tecnologia de poder diferencia-se das estruturas disciplinares e trata, sobretudo, das estimativas estatísticas, dos riscos, das medições populacionais, das intervenções nas determinações dos fenômenos globais para que se estabeleça uma regulamentação da vida, um estado global de equilíbrio, uma regularidade.

Nesse sentido, as grandes indústrias farmacêuticas não produzem exclusivamente mercadorias, mas, sobretudo, subjetividades. Na perspectiva foucaultiana, elas representam um complexo de relações de saber/poder capaz de, no tempo presente e de modo bastante expressivo, operar a conversão do ser humano em sujeito por meio de modos de objetivação, os quais são operados por práticas que permitem tornar o sujeito um objeto de saber e de poder (Foucault, 2001). Assim sendo, para Foucault (2008), a normalização biopolítica consiste em forjar comportamentos, condutas e estilos de vida, o que constitui uma estratégia de governamentalidade.

Em que pese outro foco direcionado ao estilo de vida e aos comportamentos de risco igualmente medicalizados, que incluem as 'pílulas' salvadoras dos exercícios físicos, das recomendações alimentares e de abstinência ${ }^{2}$, - encontrado numa 'nova saúde pública', o rastro do velho cuidado biomédico da saúde tem sido pautado por seu caráter curativo e, amiúde, pelo consumo de medicamentos. É preciso compreender que duas forças se unem: o desejo socialmente construído de consumir e o crescimento da oferta.

A angústia onipresente e disseminada na sociedade por meio dos riscos estabelecidos pelo estatuto epidemiológico tem garantido a necessidade de se consumir algo que a aplaque. De fato, existe uma regulamentação normativa que funciona como força de sedução. Ademais, como explica Bauman (1998), quanto maior a sedução do mercado e, conse- 
quentemente, mais elevada a procura do consumidor, mais segura e próspera será a sociedade de consumidores. ${ }^{3}$

A economia, entendida como o emprego racional e eficiente dos recursos para gerir as relações e docilizar os sujeitos, encontra sustentação na medicina contemporânea e em sua vinculação com as terapias farmacêuticas, que devem ser eficazes independentemente dos médicos. Como lembra Pignarre (1999), o que se pergunta atualmente é: "que medicamentos serão mais eficazes no seu caso?" ou "que medicamentos estou autorizado a lhe dar?". De acordo com o autor, a necessidade médica não entra em contradição com a criação do mercado; ao contrário, ambas fazem parte de um mecanismo que apreende e redefine as enfermidades, os medicamentos e, quiçá, o corpo e a própria sociedade.

Essa noção parece arraigada em diferentes situações que envolvem a ciência, a saúde e o corpo. No singular livro Biologia como ideologia, Lewontin (2000) esclarece que o projeto de sequenciamento do genoma pode envolver, além de suas funções acadêmicas, um grande negócio que visa proporcionar um imenso lucro, já que existe a possibilidade de se produzir uma vasta quantidade de mercadorias químicas/biológicas. Segundo o autor, isso ocorre a despeito do conhecimento aprofundado das causas das doenças. Lewontin debate, por exemplo, a alegação de que o conhecimento da configuração molecular de nossos genes é de grande valia para a humanidade, sem considerar que o gene associado à causa do câncer poderia ter sofrido algum tipo de alteração causada pela exposição aos agentes poluidores de um processo industrial. Assim a visão empobrecida de causa e efeito, evidenciada na ideologia dos cientistas biomédicos, tem orientado tal empreendimento. Como recorda o autor, aquilo que se apresenta sob os auspícios da ciência e do conhecimento objetivo e neutro revela-se dissimuladamente como parte da ideologia sócio-políticoeconômica.

Não custa lembrar que, muitas vezes, a busca da verdade esteve associada a diferentes formas de disciplina e controle - e, mesmo, a genocídios -, sempre conduzida em nome do progresso e/ou da ciência. O racismo de Estado, por exemplo, que asseguraria a função da morte na economia do biopoder, uma forma de 'necropolítica' em meio ao contexto biopolítico de promoção intensiva e extensiva da vida, conforme analisa Foucault (2005), esteve vinculado historicamente a argumentos de superioridade racial biológica, cientificamente respaldados, que mobilizavam 'a tese do aperfeiçoamento da humanidade' por meio da regeneração da raça humana para se legitimar, conferindo à técnica e à ciência o protagonismo desse processo. Diante do questionável libelo do progresso da humanidade, como muitos autores já apontaram, a ciência e a técnica devem ser passíveis de críticas e regulamentação quanto aos seus procedimentos, interesses e objetivos, tanto do ponto de vista epistemológico quanto ético-político.

Em nome da saúde, a ciência, por seu turno, tem produzido e comercializado suplementos alimentares que carregam consigo a promessa de um aperfeiçoamento ou reforço de capacidades não somente físicas, mas também mentais e sociais. Em termos especificamente físicos, a alegação é de que tais substâncias podem contribuir para a recuperação de esforços físicos extenuantes e para o aumento da aptidão física, ou mesmo facilitar o processo de emagrecimento. O que não se tem tornado público é que, às vezes, esses produtos mascaram substâncias consideradas doppings no meio esportivo, como os 
psicoestimulantes e anabolizantes, que podem ter efeitos adversos à saúde (Maughan, King, Lea, 2004; Baume et al., 2006).

O crescimento do número de consumidores tem sido favorecido (Bauman, 1998) pelo ampliado leque de simpáticas ofertas, geradas pela quantidade excessiva de medicamentos de mesma natureza química e eficácia, tal como ressaltou Angell (2007), ou pela facilidade de acesso, inclusive pela internet (Bessell et al., 2003; Souza, Marinho, Guilam, 2008), ou ainda pelas promessas de felicidade (Pignarre, 1999; Lewontin, 2000). Com o título "Vender remédio faz bem... para o bolso", a imprensa noticiou que as farmácias fazem parte de um negócio altamente rentável, com faturamento superior a R\$ 31 bilhões, em 2009 (crescimento em torno de 12,5\% em relação ao ano anterior). Já naquele ano, o Brasil tinha aproximadamente sessenta mil farmácias, e o Rio de Janeiro, quase duas mil além do recomendado (Ribeiro, Ribeiro, 4 out. 2009).

As indústrias farmacêuticas criam uma espécie de mercado da 'boa vida', lidando com a vida como se fosse um objeto modelável e efêmero. Tal postura levanta uma questão, pois embora as indústrias tratem de um comércio que visa ao lucro, guardam relação com o importante tema da saúde. Essa relação não deve ser tratada de modo simplesmente mercadológico, uma vez que a vida tem um caráter, por assim dizer, normativo - ou seja, envolve juízos de valor acerca do que é ser humano -, o que é irredutível a uma lógica utilitária de mercado. Sem o apoio da crítica genealógica foucaultiana, mas optando por outra de cunho normativo, a indústria farmacêutica, entendida como produtora e fornecedora de certos bens de consumo disponíveis a todo aquele que possa pagar, acabaria desviando-se de um dos seus papéis fundamentais, o de instituição gestora da saúde coletiva ou pública, uma função social de conjunto, e não particularizada, privada. Nesse sentido, Daniels (1996) defende a ideia de que, como critério de justiça, a vida deve ser priorizada como bem social fundamental, inegociável, e que as instituições de assistência à saúde, como o são as farmacêuticas, não podem ser controladas por critérios meramente mercadológicos.

Em consonância com a crescente privatização da assistência à saúde, é possível ponderar que estamos diante de uma cultura de produção de pânico moral e de doentes. Para Bauman (2008), os peritos não cessam de anunciar os perigos. Novos riscos ou ameaças são descobertos e propagados (e, provavelmente, novos 'medicamentos'), sem que se saiba, ao certo, seus reais efeitos. Para suportar o medo dos temerosos e a esperança em abrandar os riscos, a economia de consumo providencia, ao mesmo tempo, a ameaça ('a doença'), o 'remédio' (para medicalizar e/ou moralizar) e o consumidor ('o doente'). Enfim, cria medo para afirmar o biopoder.

A relação entre a privatização e a comercialização da saúde com uma espécie de fobopolítica gera um contexto muito propício para a medicalização. A promessa de prevenção e de segurança conferida pela biopolítica é extremamente atraente, mas tem um preço. O caso da pré-hipertensão é emblemático para exemplificar tal situação. Em 2003, foi publicado "The seventh report of the Joint National Comittee on Prevention, Detection, Evaluation, and Treatment of High Blood Pressure" (Chobanian et al., 2003), documento que sugeria uma série de ações para avaliar, tratar e prevenir a hipertensão arterial. Um dos pontos recomendados dizia respeito à classificação de pré-hipertenso para indivíduos com 
pressão arterial sistólica entre 120 e 139mmHg e diastólica entre 80 e $89 \mathrm{mmHg}$. Uma relevante crítica desencadeada por essa nova classificação referiu-se à ameaça de medicalização de grande parte da população adulta (Nelson, 2003). Sabemos que a engenhosidade humana desconhece limites.

\section{Considerações finais}

Refletir sobre os métodos empregados pelos laboratórios farmacêuticos para pesquisa, produção e divulgação dos medicamentos traz consigo certa estranheza. Se, por um lado, somos levados a aceitar a importância do papel que a indústria e os medicamentos representam para a saúde em geral, por outro, não tem sido rotineiro questionar algumas dificuldades nas condutas adotadas por essas empresas. Não raro, a literatura denuncia que conflitos éticos estão frequentemente presentes nas relações das indústrias com os pesquisadores e médicos.

As possibilidades abertas pelo mapeamento da concepção da biopolítica instaurada nas relações de poder sobre a vida, a partir das maquinações das indústrias farmacêuticas, envolvem novas disputas sobre a verdade e a saúde. Dessa forma, o que é singular e, ao mesmo tempo, dramático nesse processo é o tipo de ordem estabelecida, que vende ilusões e promessas em nome da saúde e da ciência. Ademais, e talvez substantivamente mais terrível, essa ordem, fundada numa retórica da prevenção, da terapia e/ou da redução de riscos para o ser humano, pode, contraditoriamente, expô-lo a mais perigos.

\footnotetext{
NOTAS

${ }^{1}$ Tradução livre.

${ }^{2}$ Foi desse modo que a indústria dos cuidados médicos se tornou um dos grandes setores econômicos e dos que mais crescem. A medicalização da vida imiscuiu-se na produção industrial e, por conseguinte, a valorização da saúde-mercadoria tornou-se reflexo da organização desse poder político-econômico (Illich, 1975).

${ }^{3}$ Ver Barros (2008), que destaca a importante influência da propaganda para a indústria farmacêutica.
}

\section{REFERÊNCIAS}

ANGELL, Marcia.

A verdade sobre os laboratórios farmacêuticos. Rio de Janeiro: Record. 2007.

ANVISA.

Agência Nacional de Vigilância Sanitária. Anvisa cancela registro do antiinflamatório Prexige. Disponível em: http://www.anvisa. gov.br/divulga/noticias/2008/220708_1.htm. Acesso em: 22 jul. 2008. 22 jul. 2008.

AWI, Fellipe.

Voluntários da cura. O Globo, Rio de Janeiro.

Revista de Domingo, p.30-35. 2 mar. 2008.
BARROS, José Augusto Cabral de. Nuevas tendencias de la medicalización. Ciência \& Saúde Coletiva, Rio de Janeiro, v.13, supl., p.579-587. 2008.

BARROS, José Augusto Cabral de; JOANY, Sabrina.

Anúncios de medicamentos em revistas médicas: ajudando a promover a boa prescrição? Ciência \& Saúde Coletiva, Rio de Janeiro, v.7, n.4, p.891-898. 2002.

BAUMAN, Zygmunt.

Medo líquido. Rio de Janeiro: Jorge Zahar. 2008. 
BAUMAN, Zygmunt.

O mal-estar da pós-modernidade. Rio de Janeiro: Jorge Zahar. 1998.

BAUME, Norbert et al.

Research of stimulants and anabolic steroids in dietary supplements. Scandinavian Journal of Medicine \& Science in Sports, Copenhagen, v.16, n.1 p.41-48. 2006.

BESSELL, Tracey L et al.

Surfing, self-medicating and safety: buying non-prescription and complementary medicines via the internet. Quality and Safety in Health Care, London, v.12, n.2, p.88-92. 2003.

BRODY, Howard.

Professional medical organizations and commercial conflicts of interest: ethical issues Annals of Family Medicine, Leawood, v.8, n.4, p.354-358. 2010.

CHOBANIAN, Aram V., et al.

The seventh report of the Joint National Committee on Prevention, Detection, Evaluation, and Treatment of High Blood Pressure: the JNC 7 report. Journal of the American Medical Association, Chicago, v.289, n.19, p.2560-2572. 2003.

DANIELS, Norman.

Health-care needs and distributive justice. In: Daniels, Norman (Ed.) Justice and justification: reflexive equilibrium in theory and practice. New York: Cambridge University Press. p.179-207. 1996.

ELLIOTT, Carl.

White coat, black hat: adventures on the dark side of medicine. Boston: Beacon Press. 2010.

FAGUNDES, Maria José Delgado et al. Análise bioética da propaganda e publicidade de medicamentos. Ciência \& Saúde Coletiva, Rio de Janeiro, v.12, n.1, p.221-229. 2007.

FOUCAULT, Michel.

Segurança, território e população: curso no Collège de France (1977-1978). São Paulo: Martins Fontes. 2008.

FOUCAULT, Michel.

A governamentalidade. In: Foucault, Michel. Microfísica do poder. Rio de Janeiro: Graal. p.278-293. 2007.

FOUCAULT, Michel.

Em defesa da sociedade: curso no Collège de France (1975-1976). São Paulo: Martins Fontes. 2005.

FOUCAULT, Michel.

El sujeto y el poder. In: Dreyfus, Hubert L.; Rabinow, Paul. Buenos Aires: Nueva Visión. p.241-259. 2001.
FUNTOWICZ, Silvio; RAVETZ, Jerry R. Emergent complex systems. Futures, Chicago, v.26, n.6, p. 568-582. 1994

GRAHAM, David J. et al.

Risk of acute myocardial infarction and sudden cardiac death in patients treated with cyclooxygenase 2 selective and non-selective nonsteroidal antiinflammatory drugs: nested casecontrol study. Lancet, London, v.365, n.9458, p.475-481. 2005.

HASS, Joanna.

Commentary: epidemiology and the pharmaceutical industry: an inside perspective. International Journal of Epidemiology, London, v.37, n.1, p.53-55. 2008.

ILLICH, Ivan.

A expropriação da saúde: nêmesis da medicina. Rio de Janeiro: Nova Fronteira. 1975.

KIRSCH, Irving et al.

Initial severity and antidepressant benefits: a meta-analysis of data submitted to the Food and Drug Administration. PLoS Medicine, San Francisco, v.5, n.2, e45. 2008.

LATOUR, Bruno; WOOLGAR, Steve.

$A$ vida de laboratório: a produção dos fatos científicos. Rio de Janeiro: Relume Dumará. 1997.

LEWONTIN, Richard C.

Biologia como ideologia: a doutrina do DNA. Ribeirão Preto: Funpec. 2000.

MARTINSON, Brian C.; ANDERSON, Melissa S.; DE VRIES, Raymond.

Scientists behaving badly. Nature, London, v.435, n.7043, p.737-738. 2005.

MAUGHAN, Ron J.; KING, Doug S.; LEA, Trevor.

Dietary supplements. Journal of Sports Sciences, London, v.22, n.1, p.95-113. 2004.

MOYNIHAN, Ray.

Obesity task force linked to WHO takes "millions" from drug firms. British Medical Journal, London, v.332, p.412. 2006.

MOYNIHAN, Ray. Controversial disease dropped from Prozac product information. British Medical Journal, London, v.328, n.7436, p.365. 2004.

MOYNIHAN, Ray.

Who pays for the pizza? Redefining the relationships between doctors and drug companies. 1: Entanglement. British Medical Journal, London, v.326, n.7400, p.1189-1192. $2003 a$.

MOYNIHAN, Ray.

Who pays for the pizza? Redefining the 
relationships between doctors and drug companies. 2: Disentanglement. British Medical Journal, London, v.326, n.7400, p.1193-1196. 2003b.

MOYNIHAN, Ray.

The making of a disease: female sexual dysfunction. British Medical Journal, London, v.326, n.7379 p.45-47. 2003c.

NELSON, Mark R.

The JNC 7 hypertension guidelines: letter. Journal of the American Medical Association, Chicago, v.290, n.10, p.1312. 2003.

NISHIOKA, Sérgio.

Desafios para a autorização de ensaios clínicos com medicamentos produzidos no Brasil. Revista da Associação Médica Brasileira, São Paulo, v.54, n.3, p.190. 2008.

PEARCE, Neil.

Corporate influences on epidemiology. International Journal of Epidemiology, Oxford, v.37, n.1, p.46-53. 2008.

PIGNARRE, Philippe.

o que é o medicamento? Um objeto estranho entre ciência, mercado e sociedade. São Paulo: Editora 34. 1999.

RIBEIRO, Fabiana; RIBEIRO, Erica.

Vender remédio faz bem... para o bolso.

O Globo, Rio de Janeiro. Seção de Economia, p.37-38. 4 out. 2009.

SCHAIRER, Catherine et al.

Menopausal estrogen and estrogen-progestin replacement therapy and breast cancer risk. Journal of the American Medical Association, Chicago, v.283, n.4, p.485-491. 2000.

SOUZA, João Fábio R. de; MARINHO, Carmem L.C.; GUILAM, Maria Cristina R.

Consumo de medicamentos e internet: análise crítica de uma comunidade virtual. Revista da Associação Médica Brasileira, São Paulo, v.54, n.3, p.225-231. 2008.

The constant gardener.

Directed by Fernando Meirelles. United Kingdom: Focus Features. 129 min. 2005.

WILLERROIDER, Marika. Making the move into drug sales. Nature, London, v.430, n.6998, p.486-487. 2004. 